\title{
Observed Behavior of Reinforced Concrete and Unreinforced Masonry Buildings in April 25, 2015 Nepal Earthquake
}

\author{
Yadin Shrestha \\ Institute of Engineering, Tribhuvan University, Nepal \\ corresponding author: yadinshrestha@yahoo.com
}

\begin{abstract}
In order to investigate the effects of devastating $7.8 \mathrm{M}_{\mathrm{w}}$ Gorkha Earthquake that struck Nepal on 25 April, 2015 and its aftershocks on reinforced concrete and unreinforced masonry buildings, a small survey team was dispatched from Institute of Engineering, Thapathali Campus. From the observation it was found that the earthquake caused extensive damages on the low-strength stone masonry buildings with no seismic detailing. In contrast, most of the reinforced concrete buildings sustained minor to some non-structural damages except in some localized places where the buildings were found to be collapsed by soft storey mechanism. The localized failure of reinforced concrete buildings in Kathmandu valley and outside may be attributed to amplification of waves in thick soft soil deposits, poor quality of construction, inadequate column sizes and lack of ductile detailing.
\end{abstract}

Keywords: Gorkha earthquake, unreinforced masonry, reinforced concrete buildings

\section{Introduction}

A 7.8 Magnitude earthquake hit in Central Nepal on April 25, 2015 at 11:56 AM (Nepal Standard Time) with epicenter $\left(28.147^{\circ} \mathrm{N}, 84.708^{\circ} \mathrm{E}\right)$ located at the Barpak Village of Gorkha District, which is nearly $80 \mathrm{~km}$ North-west of Kathmandu valley, causing extensive damages in the infrastructures and loss of more than eight thousand lives in the region. It was the largest earthquake occurred since 1934 Nepal-Bihar Earthquake of Magnitude 8.1 Mw. The two major aftershocks, with magnitude 6.6 and 6.7 occurred in the same day, while the aftershock or another main event of magnitude 7.3 $\mathrm{Mw}$ occurred in the Kodari region (northeast of Kathmandu) causing further damages in buildings and rising death toll.

A reconnaissance team from Institute of Engineering, Thapathali Campus carried out survey of the heavily affected regions (Kathmandu, Gorkha and Sindhupalchowk) to collect data on the damaged pattern experienced by reinforced concrete and masonry buildings. This paper attempts to portray the extent and nature of damages suffered by stone masonry and RC frame buildings in the recent earthquakes.

\section{Building types in Nepal}

There are mainly two types of residential buildings practiced in Nepal, viz. 1) masonry buildings with load bearing walls made of sundried and/or fired bricks in urban areas and stone masonry with mud mortar in rural areas, and 2) reinforced concrete moment resisting frame buildings. The 
first one is traditional and still practiced in rural areas of the country where modern construction materials cement/sand/aggregate and steel for reinforcement are not easily available. Wooden pillars and beams made out of tree trunks are used in these kinds of buildings. During construction of these masonry buildings, local people use their own knowledge practiced already without due consideration for the lateral load resisting system.

While, in urban areas, use of reinforced concrete is increasingly adopted in building construction which comprised cast-in-place beam, column and slab. There are two practices for the construction of infill brick masonry wall; viz. construction of infill wall before or after the casting of beam and slab. Wall constructed before slab has high stiffness due to compression force exerted by the dead load of beam and slab. In case, infill wall is constructed after casting of slab, they behave as a cantilever and prone to out-of-plane failure. For business purpose, people in urban areas have tendency to keep first floor of building open by avoiding infill walls and prefer to heve metal shutter. However, they use brick masonry infill walls in the upper floors.

\section{Damages to Reinforced Concrete Buildings}

Heavy damaged to reinforced concrete buildings in Kathmandu were observed in many places such as Gongabu, Balaju, Ramkot, Sitapaila, Manamaiju, Guheshwori, Lokanthali, Syuchatar, Bungamati, Changu Narayan, Chamati etc.
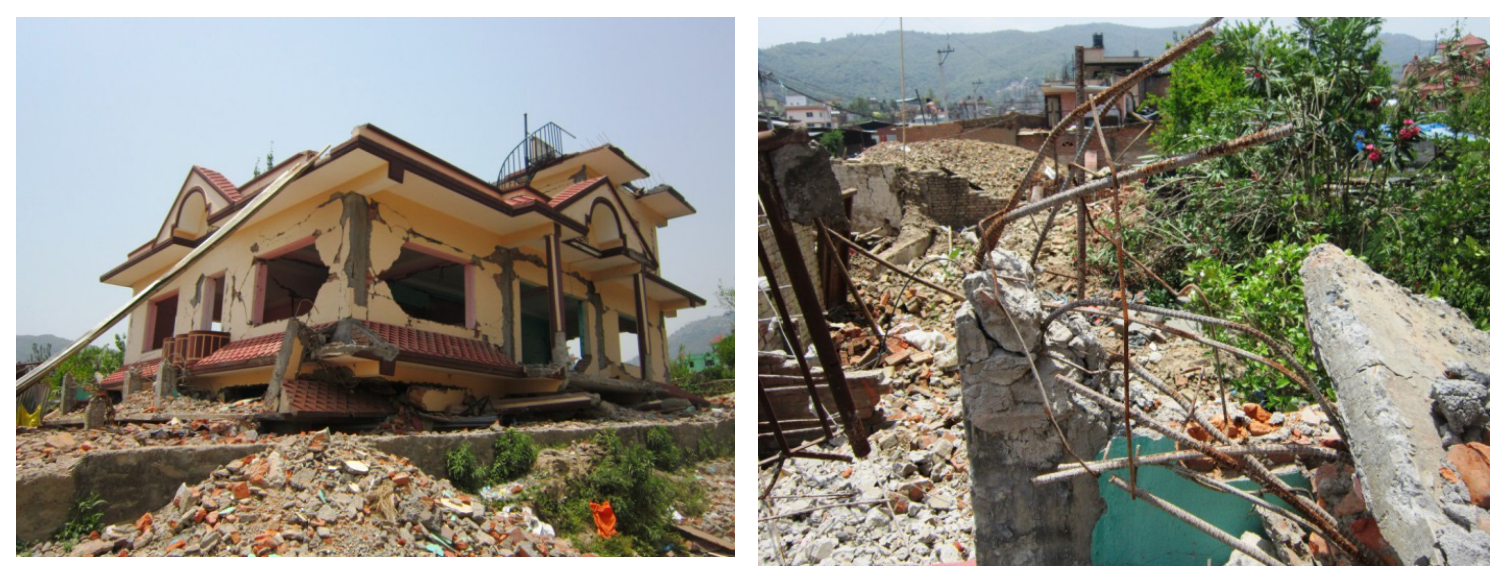

Figure 1. Collapsed RC frame building in Ramkot VDC, Kathmandu (left) and Close up view of its damaged exterior column (Right)

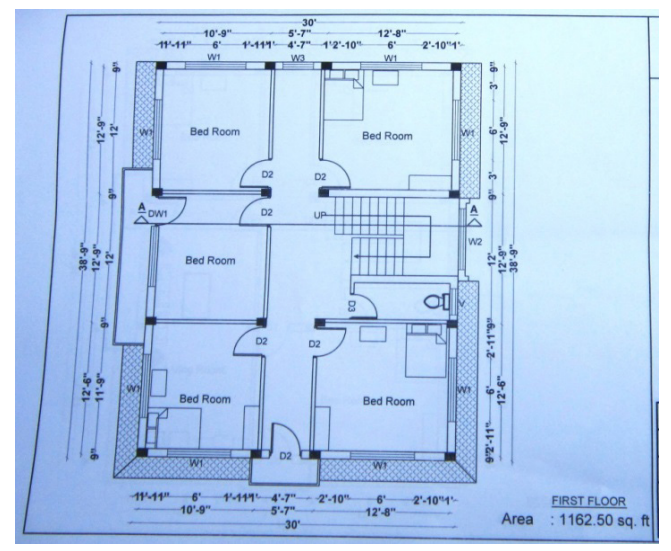

Figure 2. Architectural drawing (plan view) of building given in figure 1 
The figure 1 (left) is a recently constructed RC frame residential building at Ramkot village of Kathmandu. The building was constructed on the black cotton soil as observed in the nearby pits. This three storey building was collapsed by soft-first storey failure mechanism causing pancaking of first two stories. Structural layout of the buildings as shown in the figure 2 shows that total number of columns (size 9"x12") is 16, which are arranged symmetrically in plan area of 1162 sq.ft. The structural layout of the building seems good so far as multiple load path and regular plan is considered. But in the field it is observed that size of stirrups in columns is $6 \mathrm{~mm}$ spaced at $150 \mathrm{~mm}$ $\mathrm{c} / \mathrm{c}$ and reinforcement detailing was very poor (figure 1, right). Also, it is found that when a piece of broken concrete taken out from damaged column was pressed in the palm, it was crushed easily. So the compressive strength of concrete is expected not as much as per requirement. This indicates that presence of weak soil in the foundation, poor workmanship, and lack of ductile detailing are the major factors contributing to the collapse of this building. Similar type of failure mechanism was observed in Chamati, near Bishnumati river (Figure 3) and Gongabu area (Figure 4). These buildings had opening in the first floor and sizes of the columns were also inadequate. Addition of more stories on the same sized columns was done on both the buildings.

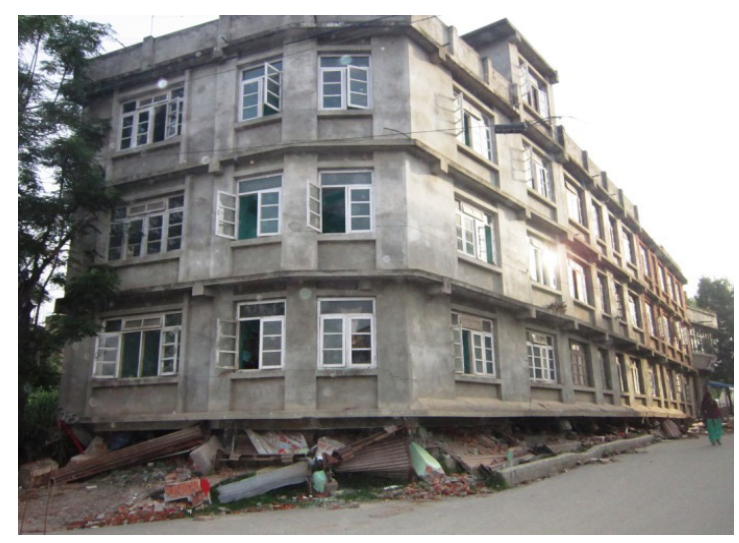

Figure 3. Soft-first storey failure of 4 storey building in Chamati, Kathmandu

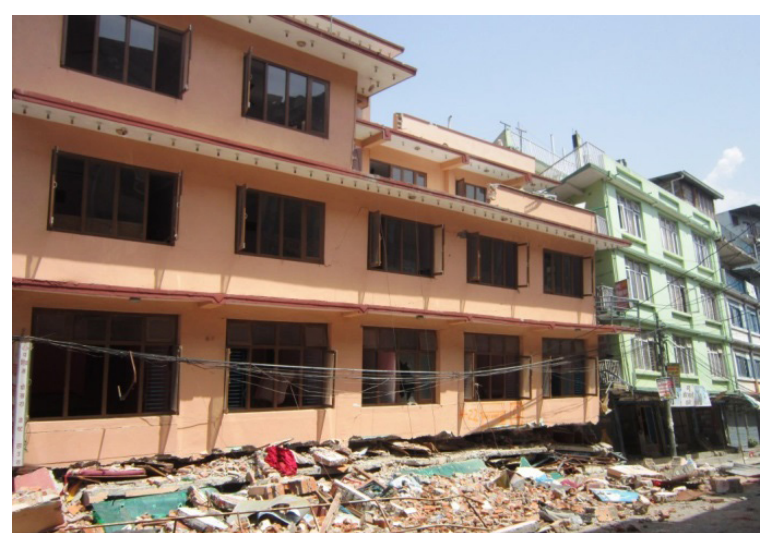

Figure 4. Soft storey failure of a guest house building in Gongabu, Kathmandu

\section{Damages to Brick Masonry Buildings}

Nowadays, construction of brick masonry buildings with load bearing walls is decreasing except for some old heritage structures. In the recent earthquake, many brick masonry buildings and heritages structures had suffered heavy damages. The figure 5 below shows the collapse of many old brick masonry buildings and still standing recently constructed RC frame building in Sankhu, Kathmandu. As seen in the figure, mostly toppling of top storey walls, out of plane failure of load bearing wall, corner separation and in some cases in-plane failure mechanism were observed. Similarly, extensive damages were observed in the Kathmandu durbar square, Patan Durbar square, Bhaktapur durbar square, and other heritage sites. 

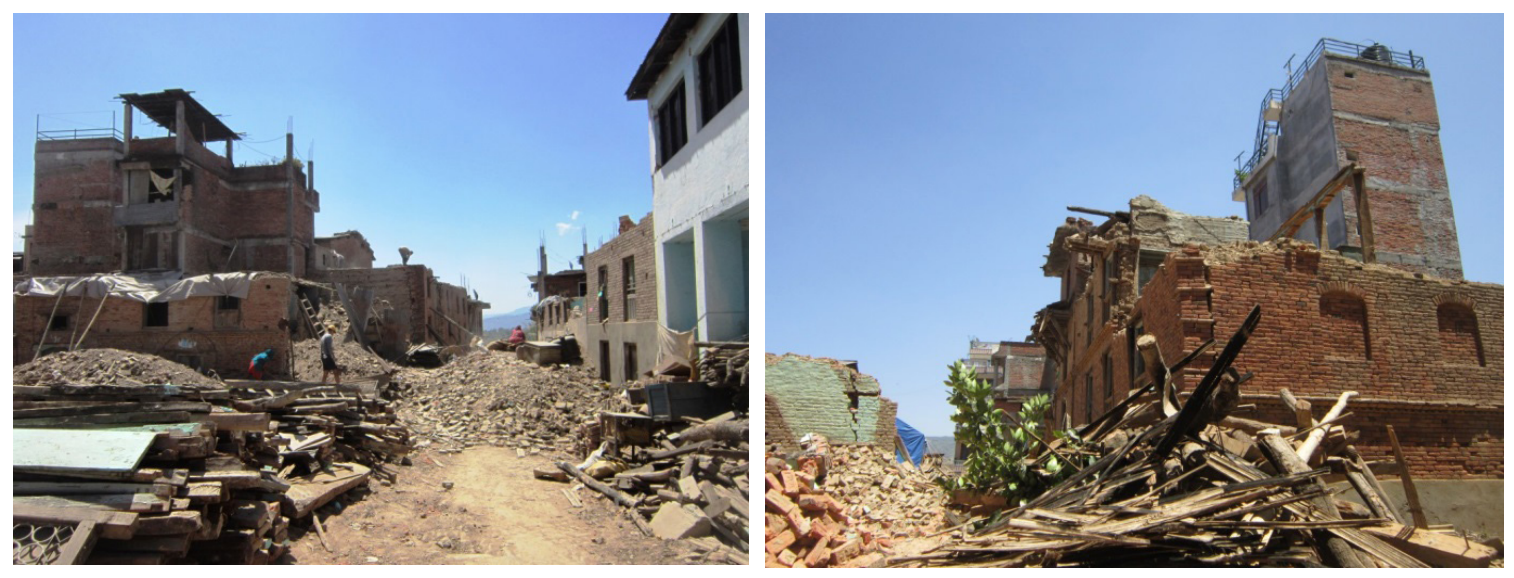

Figure 5. Collapse of old brick masonry buildings and still standing RCC building in Sankhu, Kathmandu.

\section{Damages to Stone Masonry Buildings}

In rural areas, people cannot afford construction of reinforced concrete building. For economic reason, they use locally available materials such as stone, mud and wood for the construction of their houses. This traditional type of stone masonry buildings which are mostly found in the villages were heavily suffered in the recent Nepal earthquakes, and damages were distributed all across the region. In many villages, all the houses were destroyed making whole villagers homeless. Such type of unreinforced masonry buildings are weak in tension and hence cannot resist earthquake lateral forces. Majority of the failures are out-of-plane type. The out-of-plane failure of walls of right wall and back side wall are seen in figure 6. However, good arrangement (stacking) of long regular stones at corners alternatively at adjacent faces prevented the falling of roof on the ground. Use of wooden members in the face wall prevented this wall from collapse which explains the beneficial aspects of wood in such kinds of buildings.(Figure 6)
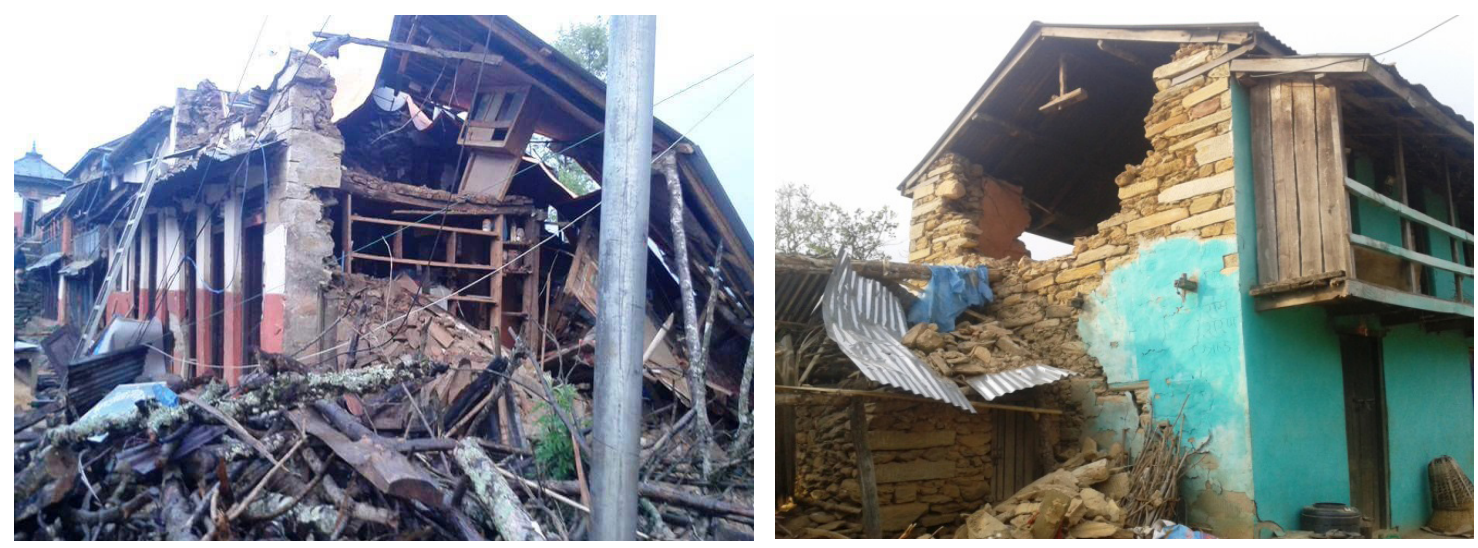

Figure 6. Collapse of stone masonry buildings with mud mortar Pipalhok village, Gorkha

Figure 7 demonstrates the development of cracks in a temple of Phinam VDC, Gorkha, which was constructed using regular shaped stones and cement mud mortar. Cross diagonal cracks are visible in the side face of the temple and a prominent gap between wall and door frame is visible in the 
front wall with door. Of course stones are very strong in compression than cement mortar and no breaking of stone is found. The stable failure mechanism called rocking can be expected during the ground shaking. However, it is also noteworthy that similar type of stone masonry houses and a temple at another village located just opposite face of the hills sustained only minor or no damages. This may be due to site effects and directivity nature of ground motion, but not confirmed yet.

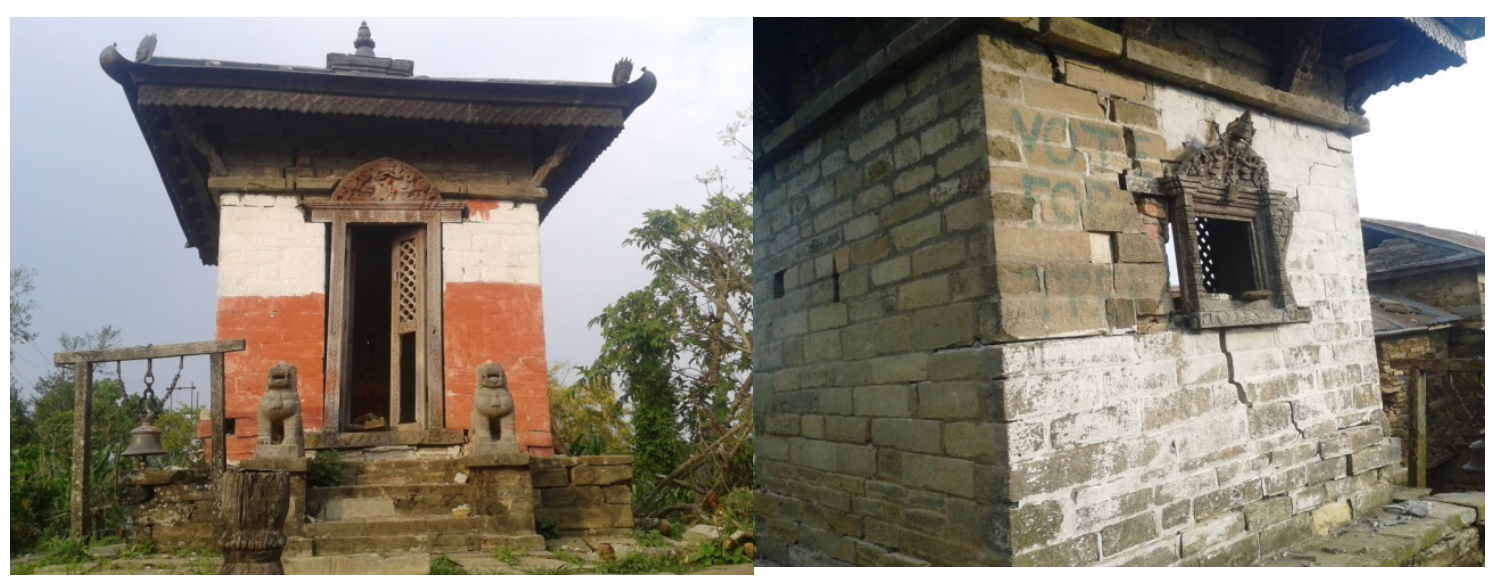

Figure 7: Diagonal Shear cracks at two side faces of Vimsen Temple at Phinam-5, Gorkha

\section{Conclusion and Recommendations}

As discussed in this paper and from the field investigation of the earthquake affected rural and urban areas, it can be concluded that the buildings constructed using stone masonry with mud mortar sustained heavy damages in the rural areas. So, it is recommended to give special attention in the construction of stone masonry buildings so that their lateral load resisting capacity will be enhanced. Use of wooden or reinforced concrete horizontal bands at appropriate locations, sill bands, lintel bands are recommended to make buildings safer in the next earthquake.

While in case of reinforced concrete moment resisting frame buildings, the prime reason for their collapse was due to soft-first story failure mechanism, inadequate column size, inadequate shear stirrups, lack of ductile detailing, poor construction practice and workmanship. In order to enhance the performance of RCC buildings, good quality control, good ductile detailing, adoption of capacity design philosophy and strict enforcement of buildings codes are required. Still a lot of research works are required to find the beneficial and harmful nature of brick infill walls in reinforced concrete structures and in developing a low cost solutions to enhance seismic resistant capacity of stone and brick masonry buildings.

\section{References}

[1] National Seismological Center (NSC), Nepal, http://seismonepal.gov.np/

[2] United States Geological Survey (USGS), earthquakes.usgs.gov

[3] GEER Association Report No. GEER-040, Version 1.0, July 29, 2015 